\title{
Oral Manifestation of Kaposi's Sarcoma in Patient with AIDS: Case Report
}

\author{
Elcio Magdalena Giovani ${ }^{1,}$, , Bruno Vieira Caputo ${ }^{1}$, Ruth Ydania Andia-Merlin ${ }^{1}$, \\ Camila Correia Dos Santos ${ }^{1}$, Rodolfo Georgevich Neto ${ }^{1}$, Kelly Cristine Tarquinio Marinho ${ }^{1}$, \\ Claudio Costa $^{2}$, Fátima Cristina Carneiro Marques ${ }^{1}$, Alfredo Mikail Melo Mesquista ${ }^{1}$, \\ Gilberto Araujo Noro Filho ${ }^{1}$ \\ ${ }^{1}$ Center for Studies and Special Service for Patients, Faculty of Dentistry, Paulista University, Institute of Health Sciences, São Paulo, Brazil \\ ${ }^{2}$ Radiology, Faculty of Dentistry, University of São Paulo, São Paulo, Brazil
}

\author{
Email address: \\ businesska@hotmail.com (E. M. Giovani) \\ ${ }^{*}$ Corresponding author
}

\section{To cite this article:}

Elcio Magdalena Giovani, Bruno Vieira Caputo, Ruth Ydania Andia-Merlin, Camila Correia Dos Santos, Rodolfo Georgevich Neto, Kelly Cristine Tarquinio Marinho, Claudio Costa, Fátima Cristina Carneiro Marques, Alfredo Mikail Melo Mesquista, Gilberto Araujo Noro Filho. Oral Manifestation of Kaposi's Sarcoma in Patient with AIDS: Case Report. American Journal of Clinical and Experimental Medicine. Vol. 5, No. 6, 2017, pp. 205-208. doi: 10.11648/j.ajcem.20170506.14

Received: August 1, 2017; Accepted: September 14, 2017; Published: November 6, 2017

\begin{abstract}
In the early 1980s, acquired immunodeficiency syndrome was recognized and described in men who had sex with previously healthy men and young people, who were affected by atypical pneumopathy caused by an opportunistic microorganism, identified as Pneumocystis carinii, and now known as Pneumocystis jiroveci, evidenced by purplish or brown nodular lesions revealed in the histopathological Kaposi's sarcoma. Kaposi's sarcoma is the most frequent neoplasm in patients with human immunodeficiency virus infection. Its pathophysiology has been associated with the presence of a herpes virus, whose etiologic agent is a member of the herpesvirus or herpes virus type 8 family(HHV-8), which can be transmitted through sexual contact, which would be implicated in the onset of the disease. This case report seeks to present the diagnosis and bring the light of knowledge to the Dentist the need to launch hands of complementary examinations and to effectively seek important therapeutic measures in the treatment of the pathology. In this case, with the start of HAART administration, the tumor regressed, leading the patient to well being, and with evident improvements in their quality of life.
\end{abstract}

Keywords: Acquired Immunodeficiency Syndrome, Kaposi's Sarcoma, Treatment

\section{Introduction}

Kaposi's Sarcoma (KS) is a malignant neoplasm of vascular origin of endothelial cells, the etiologic agent of which is a member of the herpesvirus or herpes virus type 8 (HHV-8) family, which can be transmitted through sexual contact primarily among men who have sex with Exposure to contaminated blood. Initially, Kaposi's sarcoma was described by Morris Kaposi in the year 1872 as a new pathology involving predominantly male elderly patients with multiple, hyperpigmented, nodular and more frequent lesions on the extremities of the lower limbs, and in men from the Mediterranean and Eastern European region, and or endemic disease in certain regions of Africa. Currently, it is associated with immunosuppression by HIV and / or by organ transplants. It is most commonly found on the skin of the lower limbs, visceral organs, and oral mucosa, and its epidemiology prevails in the male gender, especially in MSM (Men who have Sex with Men) and in the oral cavity, the tongue, gingiva, and palate are the most affected sites $[2,3$, $8,13,16,17,22]$.

There are four variants of KS (classical, epidemic, endemic, and post-transplant) differ not only in course and prognosis but also in terms of sites often involved. Endemic SK can be seen in the lymph nodes and internal organs, while the post-transplant and the epidemic show 
lesions in internal and mucosal organs that are usually preceded by dermal lesions. Traditionally, classic SK lesions have a general distribution, always involving the skin of the feet and legs. Patients with oral mucosal lesions may have a higher mortality rate than those with only cutaneous manifestations of $\mathrm{KS}$, characterized by lesions, smooth brown or reddish purple macula and or plaques or nodules, and can disseminate to lymph nodes and organs. Mortality of oral SK lesions may be associated with pain, bleeding and functional interferences caused by the tumor $[1,9,14,19]$.

Definitive diagnosis of $\mathrm{KS}$ is biopsied, and $\mathrm{KS}$ clinical differential diagnoses include bacillary angiomatosis, pyogenic granuloma, oral nevi, lymphoma, oral hemangiomas or other benign vascular proliferations. The treatment depends on the extent and the sites affected, with cryosurgery, alpha-interferon-in-injury, local radiation and surgical excision being the most common therapeutic options $[4,7,11,20,21]$.

HAART improves immune function and, therefore, improves the existing KS. Systemic chemotherapy treats extensive visceral involvement, which no other form of treatment can affect. The advantages of liposome formulation include increased tumor uptake. In addition, liposomes are less cardiotoxic forms. Both, Daunoxome ${ }^{\circledR} 40 \mathrm{mg} / \mathrm{m}^{2}$ every two weeks, and Caelyx ${ }^{\circledR} 20 \mathrm{mg} / \mathrm{m}^{2}$ every three weeks, showed good results in antitumor activity. The toxicity profile is better than other anthracyclines, without reported cardiotoxicity, even with high cumulative doses, but they present considerable myelosuppression, and occasional vomiting, and local treatments can be justified to improve quality of life, aesthetics, phonation, swallowing, Oral hygiene, restoration of masticatory function, and pain relief and hemorrhage $[1,5,6,18]$.

$\mathrm{KS}$ is also an opportunistic condition and the degree of immunosuppression favors the onset of the disease as observed for other opportunistic conditions of an infectious nature related to AIDS, but it is not essential for the onset of the disease $[10,12,23]$.

\section{Case Report}

A 28-year-old male patient, single, leukoderma, MSM, multiple partners, resulted in positive serology for HIV (performed using the rapid HIV test $1 / 2$ Rapid Cheek immunochromatographic method and the HIV confirmatory rapid test $1 / 2$ BIO Manguinhos, immunochromatographic method) - reagent for hepatitis $\mathrm{C}$ virus, and for syphilis (VDRL 1/64 and TPHA reagent) and confirmed by standard serological tests. At the time of diagnosis of the KS lesion in the tongue (figure 1), the patient was referred to the medical service for evaluation and conduct of his general condition, being performed abdomen ultrasound, chest Xray, MRI, not detecting any changes in normality $(300 \mathrm{mg}$ ) + lamivudine (150 mg) 1 12-12 h capsule and efavirenz $(600 \mathrm{mg}) 1$ capsule $(1 \mathrm{mg})$ and zidovudine $(300 \mathrm{mg})+$ lamivudine $(150 \mathrm{mg}) \mathrm{Night}$, only 2 weeks, immediately after the diagnosis of AIDS. At the time of the anamnesis, the patient presented CD4 + T-lymphocytes in 46 cells / $\mathrm{mm}^{3}$ of blood, CV 490.000 copies, adynamia, generalized prostration, headache, weight loss and appetite. Physical examination was weakened and palpation in the cervical chain and submandibular showed hardened, fixed and cold lymph nodes, with the largest volume being approximately $1,2 \mathrm{~cm}$ in diameter. In the intra oral clinical examination, we observed lesions on the back of the tongue, extending to the bilateral border, measuring approximately $3 \mathrm{~cm}$ in diameter and lasting 3 months, with a brown / purplish / brownish color, and in the center of the lesion showed the ulcerated fibrinolytic and necrotic bed with borders High irregular and with fetid odor, hypersalivation, and aesthetic compromise, phonation, difficulty feeding and swallowing, resulting from the volumetric increase of the tongue. The initial procedure was to perform an incisional biopsy, and the soft tissue fragment was fixed in $10 \%$ formol, stained by PAS and sent to laboratory and laboratory analysis. The results of histopathological examination were compatible with Kaposi's sarcoma (figure $2 \mathrm{a}$ and $\mathrm{b}$ and figure 3), evidenced by the presence of spindle cells, interspersed by vascular spaces similar to slits, and with the presence of extravasated erythrocytes. The diagnosis of Kaposi's sarcoma was closed before the clinical and laboratory findings. The patient was referred for treatment at a specialized site of the Unified Health Service (SUS) to assess the need for the introduction of chemotherapy. We chose to maintain HAART prescribed a few days previously, where the patient responded to satisfaction, presenting total involution of the oral lesion. In one month the patient's immune system responded positively, resulting in CD4 T-lymphocytes at 176 cells / mm 3 of blood, CV 55,000 copies. The patient was advised to return to the Infectologist and to the Dentist for monitoring, being proserved, clinically and laboratorially, without recurrence or reinfection for 14 months and until the present moment (figure 4).

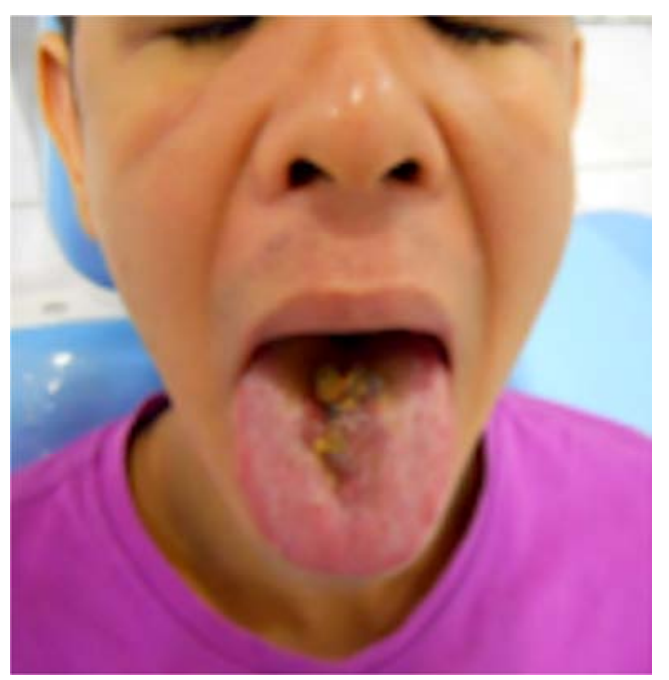

Figure 1. Injury on back of tongue. 


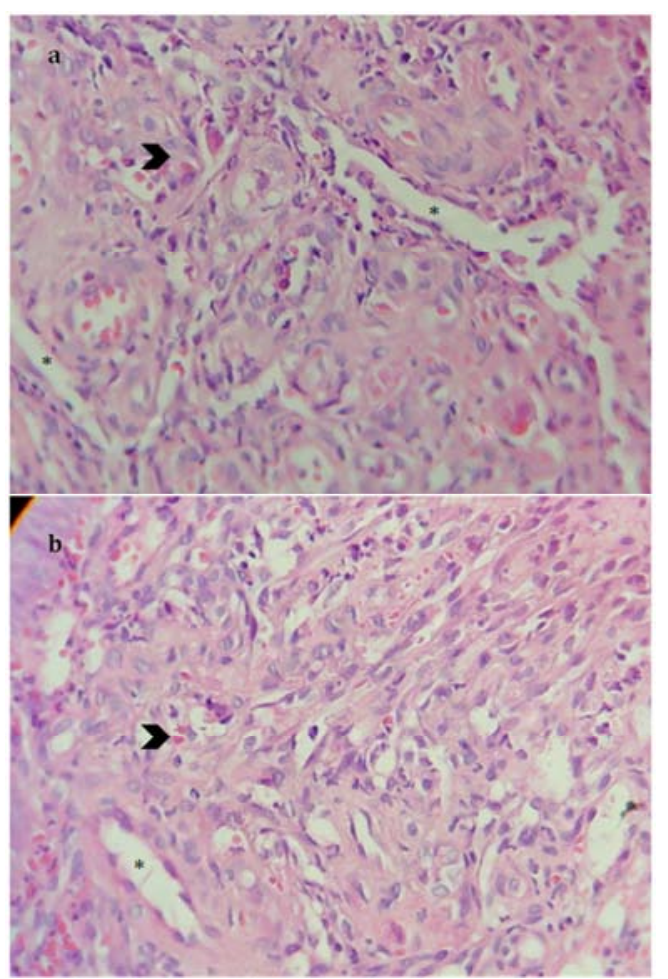

Figure 2. ( $a$ and $b)$ - Presence of spindle-shaped cells interspersed with vascular spaces (*) similar to slits, with presence of erythrocytes.

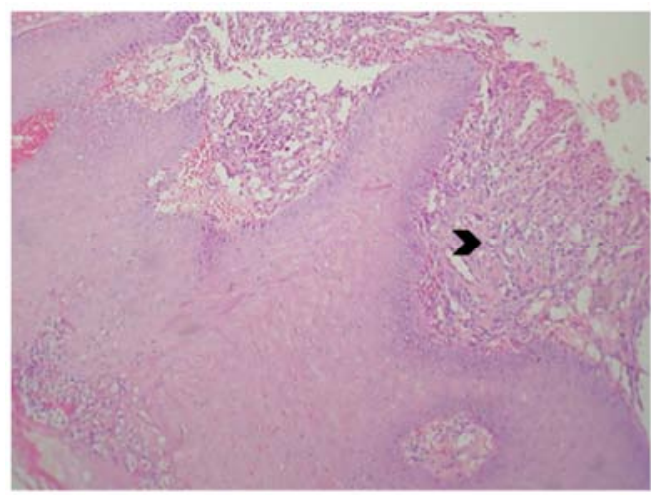

Figure 3. Neoplasia (arrowhead) observed below the surface epithelium. (100x magnification).

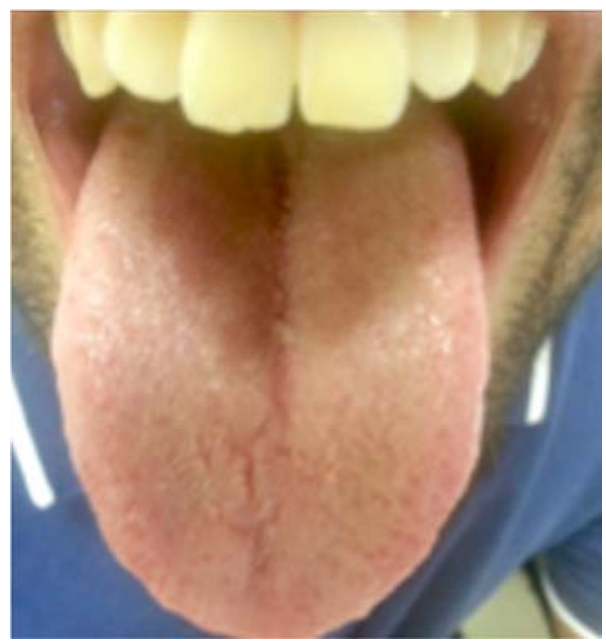

Figure 4. Tongue - Total lesion regression after 45 days of diagnosis.

\section{Discussion}

Kaposi's sarcoma is described as a malignant vascular neoplasm and at the present time is strictly related to AIDS $[1,2,3,8,13,16,17,22]$. In addition to manifestations in lower limbs and face, other lesions in the oral cavity may also be found. It is imperative for dental surgeons to have clinical knowledge of the lesions, as it can sometimes be the first to make the initial diagnosis not only of the lesion, but also of HIV seropositivity or even AIDS, as occurred in this case $[1,9,14,19]$.

The treatment of choice of KS should be based on the extent and involvement of the lesion, and it is common to associate systemic chemotherapy with local intra-lesional applications, these being evidenced as important modifying cofactors in the remission of the lesions. HAART may help to reverse the injury, although, sometimes, new manifestations may arise, even using the therapy, there is the possibility of failure of therapy, or resistance to the drugs administered and even the abandonment of treatment and even the worsening of the disease. The encapsulation of anthracycline liposomes constitutes a considerable advance in SK chemotherapy $[1,5,6,12,17,18,23]$.

\section{Conclusion}

- Kaposi's sarcoma can be diagnosed by the Dentist through clinical examination, confirming the diagnostic with achievement histopathological examination.

- It is the duty of the Dental Surgeon to have knowledge of the oral lesions that can affect the HIV / AIDS patients, mainly evidenced by the clinical characteristics compatible with each pathology.

- There are currently several forms of treatment for Kaposi's sarcoma, and it is up to the practitioner to analyze and propose together with the patient's physician the most appropriate therapy for each case.

- The association of systemic chemotherapy with local treatment (intra-lesional injections) favors the remission of lesions being an effective therapeutic option.

- Often only the fact that the patient correctly administers HAART the manifestation of SK regresses completely. Promoting health, well-being, and improvements in the quality of life of these patients.

\section{References}

[1] Shetty K. Management of oral Kaposi's sarcoma lesions on HIV-positive patient using highly active antiretroviral therapy: Case report and a review of the literature. Oral Oncology Extra, 2005,41: 226-229.

[2] Markopoulos AK; Papanayotou P;Trigonidis G. Kaposi's sarcoma of the oral cavity: Case reports. Quintessence International, 1994, 24: 415-418.

[3] Opariuc O; Napoli S; Zegarelli DJ; Yoon AJ. Recurrent and Multicentric non-HIV related Kaposi's Sarcoma. Columbia Dental Review, 2008, 12:15-18. 
[4] Mohanna S; Bravo F; Ferrufino JC; Sanchez J; Gotuzzo E. Classic Kaposi's sarcoma presenting in the oral cavity of two HIV-negative Quechua patients. Med Oral Patol Oral Cir Bucal, 2007, 12: 365-368.

[5] Sarwar N; Stebbing J; Bower M. Translation review of Aidsreleted Kaposi's sarcoma. Update on cancer therapeutics, 2007, 2: 53-60.

[6] Ozbudak IH, Guney K, Mutlu D, Gelen T, Ozbilim G. Bilateral tonsillar and esophageal Kaposi sarcoma in an HIVnegative patient. Ear Nose Throat J. 2011; 90(7):E23-6.

[7] Patrikidou A, Vahtsevanos K, Charalambidou M, Valeri RM, Xirou P, Antoniades K. Non-AIDS Kaposi's sarcoma in the head and neck area. Head Neck. 2009; 31:260-8.

[8] Tugizov SM, Webster-Cyriaque JY, Syrianen S, Chattopadyay A, Sroussi H, Zhang. Mechanisms of viral infections associated with HIV: workshop 2B. Adv Dent Res. 2011; 23(1):130-6.

[9] Vaishnani JB, Bosamiya SS, Momin AM. Kaposi's sarcoma: a presenting sign of HIV. Indian J Dermatol Venereol Leprol. 2010; 76(2):215.

[10] Wang X, Wang X, Liang D, Lan K, Guo W, Ren G. Classic Kaposi's sarcoma in Han Chinese and useful tools for differential diagnosis. Oral Oncol. 2010; 46(9):654-6.

[11] Silverberg MJ, Chao C, Leyden WA, Xu L, Horberg MA, Klein D HIV infection, immunodeficiency, viral replication, and the risk of cancer. Cancer Epidemiol Biomarkers Prev. 2011; 20(12):2551-9.

[12] Soufiane M, Fadl TM, Nawfel M, Ouafae M, Kawtar Z, Afaf L et al. Kaposi's sarcoma: HIV-negative man with isolated penile localization. Indian J Pathol Microbiol. 2010;53:535-6

[13] Martin JN. Kaposi sarcoma - associated herpesvirus/ human herpesvirus 8 and Kaposi Sarcoma. Adv Dent Res. 2011; 23(1):76-8.

[14] Mehta S, Garg A, Gupta LK, Mittal A, Khare AK, Kuldeep CM. Kaposi's sarcoma as a presenting manifestation of HIV. Indian J Sex Transm Dis. 2011; 32:108-10.

[15] Hass JR, Hasselager T. Kaposi's sarcoma interpreted as haematoma. Ugeskr Laeger. 2010;172:2388-9

[16] Messadi HYPERLINK

"http://www.ncbi.nlm.nih.gov/entrez/query.fcgi?cmd=Retrieve $\& \mathrm{db}=$ PubMed\&dopt=Abstract\&list_uids=20597946" DV, HYPERLINK

"http://www.ncbi.nlm.nih.gov/entrez/query.fcgi?cmd=Retrieve $\& \mathrm{db}=$ PubMed \&dopt $=$ Abstract\&list_uids=20597946"Younai HYPERLINK

"http://www.ncbi.nlm.nih.gov/entrez/query.fcgi?cmd=Retrieve $\& \mathrm{db}=$ PubMed\&dopt=Abstract\&list_uids=20597946" F; Aphthous ulcers. Dermatology and Therapy. 2010; 23(3):28190 .
[17] Chavan HYPERLINK

"http://www.ncbi.nlm.nih.gov/entrez/query.fcgi?cmd=Retrieve $\& \mathrm{db}=$ PubMed\&dopt $=$ Abstract\&list_uids $=22413800 "$ M, Jain H, HYPERLINK

"http://www.ncbi.nlm.nih.gov/entrez/query.fcgi?cmd=Retrieve $\& \mathrm{db}=$ PubMed\&dopt=Abstract\&list_uids=22413800"Diwan HYPERLINK

"http://www.ncbi.nlm.nih.gov/entrez/query.fcgi?cmd=Retrieve $\& \mathrm{db}=$ PubMed\&dopt $=$ Abstract\&list uids $=22413800 " \mathrm{~N}$,

Recurrentaphthous stomatitis: a review. Journal of Oral Pathology \& Medice. 2012; 41(8):577-83.

[18] Brockle HYPERLINK

"http://www.ncbi.nlm.nih.gov/entrez/query.fcgi?cmd=Retrieve $\& \mathrm{db}=$ PubMed\&dopt $=$ Abstract\&list_uids $=22972085 "$ hurst HYPERLINK

"http://www.ncbi.nlm.nih.gov/entrez/query.fcgi?cmd=Retrieve $\& \mathrm{db}=$ PubMed\&dopt=Abstract\&list_uids=22972085" P, Tickle M, HYPERLINK

"http://www.ncbi.nlm.nih.gov/entrez/query.fcgi?cmd=Retrieve $\& \mathrm{db}=$ PubMed\&dopt $=$ Abstract\&list_uids=22972085"Glenny HYPERLINK

"http://www.ncbi.nlm.nih.gov/entrez/query.fcgi?cmd=Retrieve $\& \mathrm{db}=$ PubMed \&dopt=Abstract\&list_uids=22972085" AM, Systemic interventions for recurrent aphthous stomatitis (mouth ulcers). The Cochrane Database Systematic Reviews. 2012; 9; 1-80

[19] Feily A, Rafeie E, Moosavi Z, Khazanee A, Ranjbari N, Masoumi K, Ghasemzadeh O, Safarpoor M Large Mass Arising From the Tongue as an Initially and Sole Manifestation of Kaposi Sarcoma. Internacional Journal of Medical Sciences. 2011; 8(8):709-710.

[20] Hua Huang, Ying-Ying Deng, Xiao-Hua Le, Pu-Xuan Lu Primary intraosseous Kaposi's sarcoma of the maxilla in AIDS: a case report. Quantitave Imaging in Medice Surgery. 2013; 3(6):334-338.

[21] Silva SM, Pereira AL, García-Zapata MTA Oral manifestations in HIV infection: A systematic literature review Rev. Fac. Odontol. Porto Alegre, v. 52, n. 1/3, p. 57-65, jan./dez., 2011.

[22] Arruda E, Jacome AAA, Toscano ALCC, Silvestrini AA, Rêgo ASB, Wiermann EG, Cunha Jr GFC., Melo HRLM, Morejón KML, Goldani LZ, Luiz Carlos Pereira Jr., Silva MH, Treistman MS, Pereira MCT, Romero PMBX, Schmerling RA, Guedes RAV, Camargo VP Consensus of the Brazilian Society of Infectious Diseases and Brazilian Society of Clinical Oncology on the management and treatment of Kaposi's sarcoma The Brazilian Journal of Infectious Diseases, Volume 18, Issue 3, May-June 2014, P. 315-326.

[23] Pugalagiri P, Muller S, Cox DP, Kessler HP, Wright JM, Cheng YSL Lymphangioma-like Kaposi sarcoma of the oral mucosa. Review Article Oral Surgery, Oral Medicine, Oral Pathology and Oral Radiology, Volume 116, Issue 1, July 2013, Pages 84-90. 